International Journal of Pharmaceutics \& Pharmacology

Available Online: https://ijpp.edwiserinternational.com

\title{
Using or not using anti-inflammatory drugs against Covid-19: Timeline
}

\author{
Daniel Lardizábal-Gutierrez, Ivanovich Estrada-Guel and Francisco Paraguay-Delgado*
}

Centro de Investigación en Materiales Avanzados SC (CIMAV), Av. Miguel de Cervantes 120. Complejo Industrial Chihuahua. Chihuahua, Chihuahua, México. C.P. 31136

Article info

Received 26 June 2020

Revised 22 July 2020

Available Online 28 July 2020

*Corresponding author: Francisco Paraguay-Delgado, Centro de Investigación en Materiales Avanzados SC (CIMAV), Av. Miguel de Cervantes 120. Complejo Industrial Chihuahua. Chihuahua, México. C.P. 31136

\begin{abstract}
There is great controversy about the use and non-use of anti-inflammatories during the COVID19 epidemic. From the beginning, the information that has been circulating worldwide presents contradictions. The information from the world health organization (WHO), which presents contradictions on the use of anti-inflammatory drugs, is followed up. The seriousness of these indecisions and their consequences are discussed. It is shown that, due to the indifference to attack this disease in its initial stage, by giving patients only painkillers that mask the advance of COVID-19; by making the patient think that he is healing when in fact his illness is worsening. We include a timeline where the opinions and clinical studies on this subject are observed. Including recent favourable results with the use of anti-inflammatory drugs.
\end{abstract}

Keywords: Covid-19; Coronaviruses; Anti-inflammatory; World Health Organization

\section{Short Communication}

Recently, different reports have been presented promoting anti-inflammatory drugs for the treatment of Covid-19 disease [1,2]. From the beginning, the World Health Organization (WHO) limited its use, and it was not until the beginning of June that it was recommended the use of dexamethasone (a corticosteroid) for severe patients [3]. Discouraging the use of anti-inflammatory drugs is an example of how the authorities make decisions and set guidelines for general treatments in a pandemic. Like any decision, it will have its successes and failures with the intention of carrying out a practical advance, to achieve lower deaths and harms. However, the application of a guideline based on little or misinterpreted evidence can have serious repercussions worldwide. Since the physician union worldwide is governed by its WHO standards [4-6]. Of course, when a new disease appears, knowledge is slow. As a precaution, it is better to proceed with caution while waiting for the clinical of the treatment studies and avoiding that the patient's health worsens with inappropriate medications. Unfortunately, this period could be very long, and it generates thousands of deaths as it has been seen. Perhaps fear of lawsuits has led to health agencies to be extremely cautious with their public opinions. We believe that it would be beneficial for $\mathrm{WHO}$, to pay attention to all opinions which disagree with its positions and reach a collegial agreement that minimizes the application of new protocols based on the latest evidence to shortening the time in the application of renewing protocols to save lives. At the beginning of Covid-19 disease, the recommended global protocol indicates that when a person presents symptoms, they should go to a health unit to prescribe an analgesic [7] (acetaminophen or paracetamol, in most cases). It is not until the patient has difficulty breathing, the medication is administrated to improve the disease pattern, which is already in a more complicated stage with the presence of associated diseases [8-10]. The patient's life is based on the natural selection process; if they have a good immune system, they will respond adequately to the disease and recover in a maximum of two weeks, but if they do not have the necessary defenses, they might even die. Alexis Doreski [11], who is a physician (Argentina) specializing in pulmonology and clinical researcher in internal 
Citation: Lardizábal-Gutierrez D, Estrada-Guel I, Paraguay-Delgado F. Using or not using antiinflammatory drugs against Covid-19: Timeline. Int J Pharm Pharmacol 2020; 4: 144. doi:10.31531/2581$\underline{3080.1000144}$

medicine said "Covid-19 is an inflammatory disease, it could be treated with acetaminophen, which is an antipyretic and analgesic, reaching advanced stages of the disease without fever or pain, but without stopping the inflammatory effect. We are facing an inflammatory disease, and there is no point in treating it without antiinflammatory medicine". Then, several physicians around the world have replicated this assertion. Among them, Maria Barrientos a physician from El Salvador on the same subject and several studies, reports severe inflammation caused by Covid-19, including Dr. Erika Olivia Gómez González, a principal researcher at the Autonomous University of Mexico City [12] and the Keck Medicine center of University of Southern California (USC) [13].

This report exhibits public information about the use of anti-inflammatory drugs as treatment for Covid-19 from the beginning of the pandemic until the end of May. The information comes from health bulletins from different countries and scientific studies, which, according to our criteria, are more valid in clinical medicine. The facts are presented chronologically as a timeline.

The Wuhan Municipal Health Commission (Hubei Province, China) reports a cluster of pneumonia cases in the city. It was later determined that they were caused by a new coronavirus [14] on December 31 ${ }^{\text {st }}, 2019$.

Stebbing, J. et al. published in the prestigious Journal the Lancet Infectious Diseases their article "Covid-19: combining antiviral and anti-inflammatory treatments" in which they mentioned that an excessive inflammatory response characterizes both Covid-19 and SARS; In the case of SARS, viral load is not correlated with the worsening symptoms. The use of artificial intelligence (Benevolent AI's) predicted possible treatments against Covid-19. Baricitinib, Fedratinib, and Ruxolitinib were suggested as anti-inflammatory drugs. They predicted that these drugs would be of particular importance when the host's inflammatory response becomes a major cause of lung damage and subsequent mortality [15] as on February $27^{\text {th }}, 2020$.

French health minister Oliver Veran tweeted that people with suspected Covid-19 should avoid taking antiinflammatory drugs (ibuprofen, cortisone), as they could be aggravating factors for the infection. He recommended that in the presence of fever, take acetaminophen [16] as on March 14 ${ }^{\text {th }}, 2020$.

The Spanish Agency for Medicines and Health Products (AEMPS in Spanish) announces that there is no information to guarantee that ibuprofen causes aggravation in patients with Covid-19, but this agency suggested the use of acetaminophen [17] as on March $15^{\text {th }}, 2020$.

In the current context of the Covid-19 epidemic infection, the French Minister of Health launched an appeal to warn of the risk of worsening of the infection when taking non-steroidal anti-inflammatory drugs (NSAIDs), including ibuprofen or starting cortisone therapy [18] as on March 16 ${ }^{\text {th }}, 2020$.

The next day was published "Covid-19: ibuprofen should not be used for managing symptoms, say doctors and scientists". This statement does not present the names of authors; it only references a group of highlevel scientists and physicians who support the use of acetaminophen and promote the non-use of ibuprofen mentioned by the French Minister of Health. This mention was based on four young people who aggravated their health by using ibuprofen. The document also mentioned by professors Jean-Louis Montastruc and Paul Little of University Hospital Center of Toulouse and the University of Southampton, respectively. Who commented that it is not convenient to treat infections and fever with ibuprofen and acetaminophen would cause fewer complications. Another researcher mentioned was by Ian Jones from the University of Reading and comments that the antiinflammatory properties of ibuprofen could dampen the immune system, slowing down the recovery process, based on the similarities of SARS-CoV2 and SARS I [19] as on March 17 $7^{\text {th }}, 2020$.

The declaration of the Pan American Health Organization (PAOH) issues: "Between March 15th and 18th, 2020, the WHO and other regulatory authorities such as EMA, NHS of the United Kingdom, AEMPS of the Spain and HPRA of Ireland has stated that there is currently no evidence to confirm an aggravation of Covid-19 infection through the use of ibuprofen or other NSAIDs". Then end saying that acetaminophen is prioritized to attack the symptoms of the infection [20] as on March $18^{\text {th }}, 2020$.

The WHO then issues the statement "The use of nonsteroidal anti-inflammatory drugs (NSAIDs) in patients with Covid-19". They are based on 73 studies among adults and children with viral respiratory diseases. They end by saying that there is no evidence of serious adverse events from NSAIDs use [21] as on April $19^{\text {th }}$, 2020. 
Citation: Lardizábal-Gutierrez D, Estrada-Guel I, Paraguay-Delgado F. Using or not using antiinflammatory drugs against Covid-19: Timeline. Int J Pharm Pharmacol 2020; 4: 144. doi:10.31531/2581$\underline{3080.1000144}$

The Journal of Clinical Microbiology and Infection published an article on "Ibuprofen use and clinical outcomes in Covid-19 patients". They compared the use of ibuprofen and acetaminophen in 403 confirmed cases of Covid-19, including $25 \%$ with chronic diseases. To verify if anti-inflammatory use was associated with more severe illnesses. They concluded that the clinical results find no difference in the use of acetaminophen and ibuprofen, even the death rates were similar [22] as on May $12^{\text {th }}, 2020$.

In the paper "Adjuvant corticosteroid therapy for critically ill patients with Covid-19", the study based on 244 critically ill patients concludes that its results with the use of corticosteroids increase survival in this type of patients [23] as on May 19 2020.

Other paper "The use of ibuprofen to treat fever in Covid-19: A possible indirect association with the worse outcome" was published. It is from Duke Medical School; this study promoted ibuprofen to treat fever as the first symptom of the disease. The authors based this fact that there are studies that have shown that an effective decrease in fever brings benefits in reducing the duration of viral disease and associated mortality. They suggest the hypothesis that the antipyretic effectiveness of ibuprofen would have beneficial effects when it was administered in the early stages of Covid19 [24] as on May 22 $2^{\text {nd }}, 2020$.

In the other preprint paper, "Primary care and nursing homes: About COVID 19". It presented an early care guide for older adults. In this document, the authors mentioned that there is no evidence that ibuprofen worsens the evolution of Covid-19. They even said that it is possible to administer any NSAIDs with precautions from around $6^{\text {th }}$ or $7^{\text {th }}$ day, the administration of corticosteroids in case of fever, severe fatigue, and dyspnea persisted.

Finally, at the end of May, studies on the successful use of anti-inflammatory drugs have multiplied by dozens [25] as on June $4^{\text {th }}, 2020$.

\section{Conclusion}

The public information on the use of antiinflammatories in the current pandemic is contradictory from the beginning; there are too many doubts about this subject. Among them that a twit of the French Minister of health unleashes such controversy and dictates world health policies. The French scientific community could consider the presented evidence on that date scarce. The difference in response to viral diseases between anti-inflammatory and an analgesic such as acetaminophen only masks the symptoms, making the patient believe momentary relief; when the disease continues in progress. Effective treatment at the beginning of illness is essential to prevent it from worsening. The publication by J. Stebbing et al. published in February, already mentioned an excessive inflammatory response in both SARS and Covid-19. Therefore, the use of anti-inflammatory drugs was recommended. However, the most severe thing is that even at the end of May, the protocol remains the same, only administering acetaminophen to the patient at an early stage of the disease, while evidence of the benefits of the use of anti-inflammatory drugs is already being shown. We should experience this situation, and health agencies review their protocols before giving suggestions and changing them as quickly as possible so that they are applied in a shorter time and take advantage of new treatments.

\section{Conflicts of Interests}

The authors declare no conflict of interest.

\section{Author Contributions}

All authors contributed to proposal development, write up, data collection, manuscript writing, and reviewing the manuscript.

\section{Funding}

None declared.

\section{References}

1. Hayat, W, Khan MJ. Over-the-Counter Use of Ibuprofen and COVID-19-A Controversy Resolved? Biomedica 2020; 36: Special Issue, 2020\21-Bio-65.Doc: 58-59.

2. Jahangir MA, Muheem A, Rizvi MF, et al. Coronavirus (COVID-19): History, Current Knowledge and Pipeline Medications. Int J Pharm Pharmacol 2020; 4: 140.

3. https://www.who.int/news-room/detail/16-062020-who-welcomes-preliminary-results-aboutdexamethasone-use-in-treating-critically-ill-covid19-patients; accessed June 2020

4. Phiri MN, Banda M, Mudenda S, et al. Coronavirus Disease 2019 (COVID-19): The Role of Pharmacists in the Fight against COVID-19 Pandemic. Int J Pharm Pharmacol 2020; 4: 143. 
Citation: Lardizábal-Gutierrez D, Estrada-Guel I, Paraguay-Delgado F. Using or not using antiinflammatory drugs against Covid-19: Timeline. Int J Pharm Pharmacol 2020; 4: 144. doi:10.31531/2581$\underline{3080.1000144}$

5. Mudenda S. Letter to Editor: Coronavirus Disease (COVID-19): A Global Health Problem. Int J Pharm Pharmacol 2020; 4: 141.

6. https://www.who.int/es/emergencies/diseases/nove 1-coronavirus-2019/technical-guidance; accessed June 2020.

7. http://coronavirus.onu.org.mx/el-ibuprofeno-esperjudicial; accessed June 2020.

8. Irfan M. Letter to Editor: Steps and Measure to Stop the Spread of COVID-19. Int J Pharm Pharmacol 2020; 4: 142.

9. Hassan M, Savitri VVS, Tanveer N, et al.A Prospective Observational Study on Management of Acute Coronary Syndrome in A Multi-Specialty Hospital. Int J Gen Med Surg2019; 3:124.

10. Zhang S, Li D, Chen $\mathrm{H}$, et al. The dynamic inflammatory response in a critically ill COVID-19 patient treated with corticosteroids. J Zhejiang University (Medical Science) 2020; 49: 220-226.

11. https://www.infobae.com/america/tendenciasamerica/2020/06/11/ibuprofeno-y-coronavirus-notiene-logica-tratar-el-covid-19-sin-unantiinflamatorio/

12. https://www.eleconomista.com.mx/arteseideas/Co vid-19-una-enfermedad-no-solo-pulmonar-sinosistemica-20200519-0145.html; accessed June 2020

13. https://hscnews.usc.edu/keck-medicine-of-usclaunches-clinical-trial-to-study-anti-inflammatorydrug-as-treatment-for-covid-19

14. https://www.who.int/news-room/detail/27-042020-who-timeline---covid-19. Consulted May 2020.

15. Stebbing J, Phelan A, Griffin I, et al. COVID-19: combining antiviral and anti-inflammatory treatments. Lancet Infect Dis 2020; 20: 400-402.
16. OlivierVéran:https://twitter.com/olivierveran/statu s/1238776545398923264; accessed May 2020.

17. https://www.aemps.gob.es/informa/notasinformati vas/medicamentosusohumano-3/2020medicamentosusohumano-3/la-aemps-informaque-ningun-dato-indica-que-el-ibuprofeno-agravelas-infecciones-por-covid-19/; accessed May 2020.

18. COVID-19:pas d'AINS! et respect de bon usage du paracétamol... Available at https://www.rfcrpv.fr/covid-19-pas-dains-etrespect-du-bon-usage-du-paracetamol/; accessed May 2020

19. Day M. COVID-19: ibuprofen should not be used for managing symptoms, say doctors and scientists. BMJ 2020; 368: m1086

20. https://www.paho.org/en/news/18-3-2020announcement-about-ibuprofen-and-covid-19washington-dc-18-march-2020; accessed May 2020.

21. https://www.who.int/publications/i/item/the-useof-non-steroidal-anti-inflammatory-drugs-

(NSAIDs)-in-patients-with-COVID-19; accessed May 2020.

22. Rinott E, Kozer E, Shapira Y, et al. Ibuprofen use and clinical outcomes in COVID-19 patients. Clinic Microbiol Infect 2020; Article in Press.

23. Lu X, Chen T, Wang $\mathrm{Y}$, et al. Adjuvant corticosteroid therapy for critically ill patients with COVID-19. Critic Care 2020; 24: 1-4.

24. Jamerson B, Haryadi TH. The Use of Ibuprofen to Treat Fever in COVID-19: A Possible Indirect Association with Worse Outcome? Medical Hypotheses 2020; 109880.

25. Blanco E. Atencion Primaria y Residencias de Ancianos: A Proposito de la COVID-19. Medicina de Familia. SEMERGEN 2020.

This manuscript was peer-reviewed

Mode of Review: Single-blinded

Academic Editor: Dr. Shakir Saleem

Copyright: (92020 Lardizábal-Gutierrez D, et al. This article is distributed under the terms of the Creative Commons Attribution 4.0 International License (http://creativecommons.org/licenses/by/4.0/), which permits unrestricted use, distribution, and reproduction in any medium, provided you give appropriate credit to the original author(s) and the source, provide a link to the Creative Commons license, and indicate if changes were made. 